\title{
Additive effects of a two-amino-acid insertion and a single-amino-acid substitution in dihydropteroate synthase for the development of sulphonamide-resistant Neisseria meningitidis
}

\author{
Yvonne Qvarnström and Göte Swedberg
}

\begin{abstract}
Author for correspondence: Göte Swedberg. Tel: +46 1847146 19. Fax: +46 18502790. e-mail: gote.swedberg@farmbio.uu.se
\end{abstract}

Department of

Pharmaceutical Biosciences, Division of Microbiology, Biomedical Centre, Uppsala University, Box 581, S-751 23 Uppsala,

Sweden

\begin{abstract}
Sulphonamide resistance in some clinical isolates of Neisseria meningitidis is associated with an insertion in the chromosomal folP gene leading to the addition of two amino acids, serine and glycine, in the drug target enzyme dihydropteroate synthase (DHPS). Removal of the insertion resulted in a markedly higher $K_{\mathrm{m}}$ for the substrate $p$-aminobenzoic acid and a markedly lower $K_{m}$ for 2-amino-4-hydroxy-6-(hydroxymethyl)-7,8-dihydropteridine pyrophosphate. In the same isolates an additional important difference, compared to wild-type enzymes, was found at amino acid position 68 , which is a proline in most DHPS enzymes, but is serine in one and leucine in another clinical isolate of sulphonamide-resistant $\boldsymbol{N}$. meningitidis. The alteration at position 68 was found to affect mainly the level of sulphonamide resistance and had only a minor effect on the $K_{m}$ for the substrates. Introduction of the serine-glycine dipeptide at position 194 and a proline to serine substitution at position 68 in DHPS from normal, susceptible $N$. meningitidis failed to produce a functional sulphonamide-resistant enzyme. The conclusion of this study is that it is not possibile to change a normal chromosomally encoded DHPS of $\boldsymbol{N}$. meningitidis to a sulphonamide-resistant one simply by an insertion of serine and glycine as seen in clinical isolates. It is likely that the resistance gene found in clinical isolates has evolved in another bacterial species where a combination of other amino acid changes may have contributed to produce a functionally resistant enzyme. This new resistance gene may have then been introduced into $\boldsymbol{N}$. meningitidis by natural transformation.
\end{abstract}

Keywords: Neisseria meningitidis, sulphonamide resistance, dihydropteroate synthase, site-directed mutagenesis

\section{INTRODUCTION}

Development of drug resistance in pathogenic bacteria can be considered as an adaptation process with a balance between beneficial and deleterious effects on function. Several experiments have shown that mutational alterations leading to resistance may cause an initial loss of survival value for the bacteria affected, but that compensatory mutations that increase the fitness may also occur rapidly and lead to stable resistant

Abbreviations: DHPS, dihydropteroate synthase; $\mathrm{pAB}, p$-aminobenzoic acid; pteridine, dihydropteridine pyrophosphate. variants of the bacteria. Models for the development of resistance and fixation of mutations have been presented (Björkman et al., 1998; Levin et al., 1997; Schrag \& Perrot, 1996; Stuart et al., 1998).

Sulphonamide resistance in Neisseria meningitidis may serve as an example of how well-adapted resistant strains have emerged from the original susceptible strains. Sulphonamide-resistant strains have been isolated from patients with meningitis and from healthy carriers that have not been treated with sulphonamide drugs. These strains should thus be considered well adapted since they obviously can survive in competition with other bacteria in humans in the absence of selective 

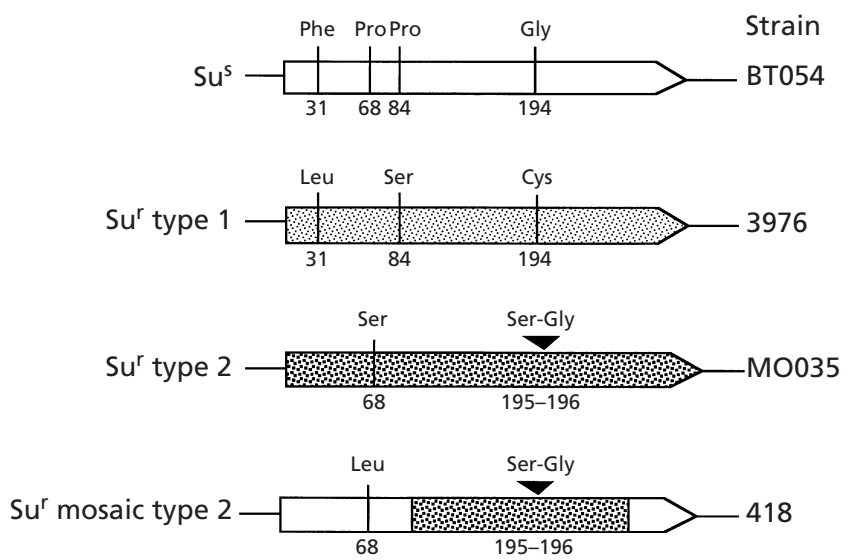

Fig. 1. Comparison between folP genes from strains of $N$. meningitidis. Strain BT054 represents the sulfonamidesusceptible group. Strains 3976 and MO035 are representative of the two types of resistance determinants. Strain 418 has a mosaic folP gene. Relevant deviations are marked with vertical lines along the genes, where the number below indicates the amino acid number in the DHPS polypeptide. The Ser-Gly insertion is marked with a black triangle.

pressure caused by the use of sulphonamide drugs (Fermér et al., 1995; Fermér \& Swedberg, 1997; Rådström et al., 1992).

Two types of resistant folP genes have so far been found in clinical isolates of N. meningitidis (Fig. 1). Type 1 may be considered as mutationally altered wild-type genes. These genes have a low sequence divergence $(<4 \%)$ when compared to folP genes from susceptible isolates (Fermér et al., 1995). Positions where the folP genes of resistant meningococci differ from those of susceptible isolates were identified. The amino acids at these positions were changed to the consensus sequence by site-directed mutagenesis. The importance of the amino acid changes was shown by changes in the kinetic properties of the mutated enzymes (Fermér \& Swedberg, 1997).

Type 2 genes are distinguished from type 1 by a much more extensive sequence divergence. The resistant strain MO035 has a type 2 gene and it differs from the folP gene of susceptible strains by $10 \%$. Type 2 genes have an apparent insertion of six base pairs, leading to a Ser-Gly insertion in a conserved region of the protein (Fig. 1). From these observations it has been suggested that these type 2 genes have been introduced from another bacterial species (Rådström et al., 1992). Further evidence for horizontal transfer of resistance genes was found in the resistant strain 418. This strain has a folP gene with a mosaic structure (Fig. 1), where a central part of the normal, meningococcal gene has been replaced by the corresponding part of a resistance gene identical to that of strain MO035. Although half of the dihydropteroate synthase (DHPS) enzyme in strain 418 is identical to wild-type meningococcal DHPS, this enzyme confers a high level of resistance to sulphonamides. DHPS enzymes from the resistant strains
MO035 and 418 were previously found to have $K_{\mathrm{m}}$ values for $p$-aminobenzioc acid $(\mathrm{pAB})$ that were ten times higher than for susceptible isolates (Fermér \& Swedberg, 1997). Both MO035 and 418 have the same Ser-Gly insertion at amino acid positions 195-196 of their DHPS enzymes. Deletion of these two extra amino acids caused the resistance to disappear for both enzymes. (Fermér \& Swedberg, 1997). Since the type 2 resistance genes differ at a large number of positions from the DHPS of susceptible isolates and probably have been introduced from a so far unknown source, it is not possible to draw any conclusions about the evolution process regarding these genes from sequence comparisons only. Results from experiments where these genes have been changed back to the susceptible type would help to inform the debate. These results could then be used to introduce the pertinent mutations into a wild susceptible strain to test the conclusions.

Here we present results from such a strategy. The effect of removing the Ser-Gly insertion from a type 2 DHPS was studied by enzyme kinetic determinations for $\mathrm{pAB}$ and dihydropteridine pyrophosphate (pteridine). An additional amino acid change important for resistance development was identified at position 68. We then took a normal susceptible variant of $N$. meningitidis DHPS and introduced the additional Ser-Gly dipeptide, as well as the alteration at position 68. Both of these changes slightly changed the $K_{\mathrm{i}}$ for sulphathiazole; however, they also resulted in production of a severely defective enzyme. This finding led to the conclusion that development of type 2 resistance from the susceptible $N$. meningitidis DHPS is unlikely. These results reinforce the argument that the type 2 resistance gene is a foreign gene that probably has been brought into N. meningitidis by transformation.

\section{METHODS}

Bacterial strains and media. Escherichia coli strain $\mathrm{DH} 5 \alpha$ was grown on LB medium (Bertani, 1951), Iso-Sensitest Agar (Oxoid) or $2 \times$ TY broth (Müller-Hill et al., 1968). The knockout mutant of E. coli C600 lacking folP, C600 $\Delta$ folP : : Km ${ }^{\mathrm{R}}$ (Fermér \& Swedberg, 1997), was grown on LB medium or, when complemented with a functional folP, on Iso-Sensitest Agar. The growth medium was supplemented with $50 \mu \mathrm{g}$ ampicillin $\mathrm{ml}^{-1}$ and $40 \mu \mathrm{g}$ kanamycin $\mathrm{ml}^{-1}$ when appropriate.

Site-directed mutagenesis. The hemimethylation protection method of Vandeyar et al. (1988) was used for construction of most mutants. Primer RM5 (5'-GAATCGACGCGGCCGGGTGCGGATTATGTTTC-3') was used to change T to C in codon 68 in strains MO035 and 418. Primer RM7 (5'-GAATCGACGCGGTCGGGTGCGGATTATG-3') was used to change $\mathrm{C}$ to $\mathrm{T}$ in codon 68 in strain BT054. The $6 \mathrm{bp}$ insertion $\left(5^{\prime}\right.$-TCCGGC-3') was introduced by the PCR-based 'megaprimer' mutagenesis method (Sarkar \& Sommer, 1990) using primers RM6 (5'-CGCTCGATCCGGGTTTCGGCTCCGGCTTCGGCAAAACCCTGCAACAC-3') and NM2 (Rådström et al., 1992) in the first PCR. The obtained megaprimer was purified by the QIAquick Gel Extraction kit (Qiagen) and used together with primer NM1 (Rådström et al., 1992) to recover the whole gene. The required clones were 
identified by sequence determination using the Cy5 Autoread Sequencing method on an ALFexpress DNA sequencer (Pharmacia Biotech). The insertion in BT054 was also verified by size determinations: the mutated region was PCR amplified with primers NM6 (Rådström et al., 1992) and NM10 (5'GCAGGCATCGCACCGCAACG-3') and the amplimer was run on a $8 \%$ polyacrylamide gel, which could separate the mutated $110 \mathrm{bp}$ fragment from the original $104 \mathrm{bp}$ fragment. Mutated folP genes were cloned in pUC18 and pUC19 vectors (Yannisch-Perron et al., 1985) and transformed into DH5 $\alpha$ by electroporation (Dower et al., 1988).

MIC determinations. Cloned folP genes were transformed into C600 folP:: $\mathrm{Km}^{\mathrm{R}}$. Sulphonamide susceptibility was tested as previously described (Fermér et al., 1995) using sulphathiazole at concentrations ranging from 0.02 to $5 \mathrm{mM}$. Some MIC values in this work differ from corresponding values presented earlier (Fermér et al., 1995) because of the use of different $E$. coli host cells.

Determination of enzyme kinetic parameters. Enzyme preparations were made as previously described (Fermér \& Swedberg, 1997), except that disruption of the cells was by sonication. Enzyme activity was measured by incorporation of radiolabelled $\left[{ }^{14} \mathrm{C}\right] \mathrm{pAB}$ in pseudo-first-order reactions, as previously described (Fermér \& Swedberg, 1997). $K_{\mathrm{m}}$ and $K_{\mathrm{i}}$ values were determined using the GraphPad Prism program for Macintosh (GraphPad Software). Standard deviations were calculated from at least five independent measurements.

\section{RESULTS}

\section{Amino acid changes at position 68 in DHPS enhances sulphonamide resistance}

Removal of the two amino acids Ser-Gly from the DHPS of MO035 increase their $K_{\mathrm{m}}$ values for pAB tenfold and lower the $K_{i}$ for sulphathiazole tenfold (Fermér \& Swedberg, 1997). Since sensitive enzymes usually have $K_{\mathrm{m}}$ values that are much lower than those for resistant enzymes (around $0.3 \mu \mathrm{M}$ for sensitive enzymes compared to around $3 \mu \mathrm{M}$ for resistant), we did not expect to find that the $K_{\mathrm{m}}$ values for the sensitive enzymes lacking the insertion were actually much higher than those of the resistant MO035 or 418 enzymes. This observation may possibly be explained by the fact that there are additional compensatory mutations in the resistant enzymes that lower the $K_{\mathrm{m}}$ to an acceptable level. Possible compensatory mutations are, unfortunately, masked within the sequence divergence between resistant type 2 folP genes and other meningococcal folP genes. One possible important residue was identified at position 68, where the MO035 enzyme has a Ser residue and that of 418 has a Leu residue instead of the wellconserved Pro found in the consensus sequence. Accordingly, position 68 was changed to a Pro in the mutated MO035 and 418 DHPS enzymes lacking the insert. These mutant enzymes do not confer sulphonamide resistance. The additional mutation at position 68 did not restore this ability. Instead, this mutation was found primarily to affect the affinity of the enzymes for pAB (Table 1). The $K_{m}$ for pAB was almost tenfold lower for the enzymes with the double mutation compared to those that had lost only the insertion, indicating that in a DHPS without the Ser-Gly insertion, Pro at position 68 gives a lower $K_{m}$ than Ser. Changing Ser to Pro in the original form of resistant DHPS, i.e. with the Ser-Gly insert, gave the lowest $K_{m}$ for pAB but also a lower $K_{i}$ value and consequently a lower MIC value (Table 1). The same phenomenon was found with the 418 enzyme after changing its Leu to Pro. It was thus concluded that the amino acid change at position 68 was a mutation that resulted primarily in a higher level of resistance in the host than that conferred by the enzyme with only the Ser-Gly insertion.

\section{Effects of DHPS alterations on the $K_{\mathrm{m}}$ for pteridine}

The affinity for the other substrate, pteridine, was affected in a different way to pAB (Table 1). DHPS enzymes from resistant isolates were found to have very high $K_{m}$ values for pteridine: approximately ten times

Table 1. Kinetic properties of resistant type 2 DHPS enzymes before and after site-directed mutagenesis

Determinations of the kinetic properties were made after cloning the genes in C600 $f$ folP::Km ${ }^{\mathrm{R}}$. STZ, sulphathiazole; ND, not determined.

\begin{tabular}{|c|c|c|c|c|c|c|}
\hline \multirow[t]{2}{*}{ Strain } & \multicolumn{2}{|c|}{ Amino acid composition } & \multirow{2}{*}{$\begin{array}{c}\mathrm{pAB} \\
K_{\mathrm{m}} \pm \mathrm{SD}(\mu \mathrm{M})\end{array}$} & \multirow{2}{*}{$\begin{array}{c}\text { Pteridine } \\
K_{\mathrm{m}} \pm \operatorname{SD}(\mu \mathrm{M})\end{array}$} & \multirow{2}{*}{$\begin{array}{c}\mathrm{STZ} \\
K_{\mathrm{i}} \pm \operatorname{SD}(\mu \mathrm{M})\end{array}$} & \multirow{2}{*}{$\begin{array}{l}\text { STZ MIC } \\
\quad(\mathbf{m M})\end{array}$} \\
\hline & Position 68 & $\begin{array}{c}\text { Ser-Gly } \\
\text { insertion }\end{array}$ & & & & \\
\hline MO035 & Ser & Yes & $2 \cdot 4 \pm 0 \cdot 3 *$ & $28 \pm 6$ & $120 \pm 19^{*}$ & $2 \cdot 0$ \\
\hline MO035 ( $\Delta$ SG) & Ser & No & $38 \pm 6^{*}$ & $1 \cdot 7 \pm 0 \cdot 4$ & $12 \pm 1 *$ & $0 \cdot 10$ \\
\hline $\operatorname{MO035}(\mathrm{S} \rightarrow \mathrm{P})$ & Pro & Yes & $1 \cdot 5 \pm 0 \cdot 2$ & $36 \pm 6$ & $3 \pm 1$ & $1 \cdot 5$ \\
\hline $\operatorname{MO035}(\Delta \mathrm{SG}, \mathrm{S} \rightarrow \mathrm{P})$ & Pro & No & $5 \cdot 7 \pm 0 \cdot 7$ & $2 \cdot 3 \pm 1 \cdot 1$ & $0 \cdot 9 \pm 0 \cdot 1$ & ND \\
\hline 418 & Leu & Yes & $3 \cdot 8 \pm 0 \cdot 8 *$ & $\mathrm{ND}$ & $141 \pm 13 *$ & $\geqslant 5 \cdot 0$ \\
\hline $418(\Delta \mathrm{SG})$ & Leu & No & $33 \pm 2 *$ & ND & $30 \pm 13 *$ & $0 \cdot 25$ \\
\hline $418(\mathrm{~L} \rightarrow \mathrm{P})$ & Pro & Yes & $2 \cdot 7 \pm 0 \cdot 5$ & ND & $13 \pm 2$ & $1 \cdot 5$ \\
\hline $418(\Delta \mathrm{SG}, \mathrm{L} \rightarrow \mathrm{P})$ & Pro & No & $4 \cdot 4 \pm 0 \cdot 8$ & ND & $1 \cdot 5 \pm 0 \cdot 1$ & ND \\
\hline
\end{tabular}

*From Fermér \& Swedberg (1997). 
Table 2. Kinetic properties of DHPS enzymes from strain BT054 before and after site-directed mutagenesis

Determinations of kinetic properties were made after cloning the genes in C600 $\Delta$ folP:: Km ${ }^{\mathrm{R}}$. STZ, sulphathiazole; wt, wild-type.

\begin{tabular}{|c|c|c|c|c|c|c|}
\hline \multirow[t]{2}{*}{ Strain } & \multicolumn{2}{|c|}{ Amino acid composition } & \multirow{2}{*}{$\begin{array}{c}\mathrm{pAB} \\
K_{\mathrm{m}} \pm \mathrm{SD}(\boldsymbol{\mu M})\end{array}$} & \multirow{2}{*}{$\begin{array}{c}\text { Pteridine } \\
K_{\mathrm{m}} \pm \operatorname{SD}(\boldsymbol{\mu M})\end{array}$} & \multirow{2}{*}{$\begin{array}{c}\mathrm{STZ} \\
\boldsymbol{K}_{\mathrm{i}} \pm \operatorname{SD}(\boldsymbol{\mu M})\end{array}$} & \multirow{2}{*}{$\begin{array}{l}\text { STZ MIC } \\
\quad(\mathbf{m M})\end{array}$} \\
\hline & Position 68 & $\begin{array}{l}\text { Ser-Gly } \\
\text { insertion }\end{array}$ & & & & \\
\hline BT054 wt & Pro & No & $0 \cdot 3 \pm 0 \cdot 1^{*}$ & $3 \cdot 6 \pm 1 \cdot 1$ & $0 \cdot 10 \pm 0 \cdot 05^{*}$ & $0 \cdot 10$ \\
\hline BT054 (+SG) & Pro & Yes & $32 \pm 6$ & $10 \pm 3$ & $1 \cdot 2 \pm 0 \cdot 2$ & $<0.02$ \\
\hline BT054 $(\mathrm{P} \rightarrow \mathrm{S})$ & Ser & No & $5 \cdot 2 \pm 0 \cdot 7$ & $2 \cdot 9 \pm 0 \cdot 5$ & $0 \cdot 7 \pm 0 \cdot 1$ & $0 \cdot 02$ \\
\hline $\mathrm{BT} 054(+\mathrm{SG}, \mathrm{P} \rightarrow \mathrm{S})$ & Ser & Yes & $78 \pm 10$ & $7 \pm 2$ & $46 \pm 2$ & $<0.02$ \\
\hline
\end{tabular}

*From Fermér \& Swedberg (1997).

higher than enzymes from sensitive strains. The removal of the Ser-Gly insertion in the MO035 enzyme resulted in a tenfold drop in $K_{\mathrm{m}}$ for pteridine, reducing it to the same level as found for sensitive enzymes. Mutations at position 68, on the other hand, had no significant influence on the pteridine $K_{\mathrm{m}}$. For comparison, we also determined the $K_{\mathrm{m}}$ for pteridine of the type 1 DHPS from strain $3976(37 \mu \mathrm{M})$, which was found to be in the same range as that for the MO035 DHPS $(28 \mu \mathrm{M}$; Table 1).

\section{Introduction of mutations determining resistance into a sulphonamide-susceptible DHPS}

The results from the mutagenesis studies presented here were used to try to change the DHPS from a susceptible strain into a form that would confer resistance to sulphonamides. The Ser-Gly insertion was introduced into the BT054 polypeptide at the same position as found in the MO035 enzyme. This had a dramatic effect, raising the $K_{m}$ for both substrates (Table 2). However, the insertion affected the enzymic function adversely, because the ability to complement an E. coli strain lacking the chromosomal folP gene was significantly lower for this mutant than for wild-type genes as well as all the mutants mentioned above. The generation time of C600 $\mathrm{folP}$ with a plasmid containing the BT054 gene with the insertion was around $1 \mathrm{~h}$. A clone with the original BT054 gene has a generation time of $30 \mathrm{~min}$. The mutated BT054 enzyme did not allow growth in the presence of any concentration of sulphathiazole tested. However, the $K_{\mathrm{i}}$ for sulphathiazole was slightly raised for the mutant compared to the original BT054 enzyme, but the $K_{\mathrm{m}}$ for $\mathrm{pAB}$ was raised much more.

Changing the amino acid at position 68 in the BT054 enzyme, from the conserved Pro to the Ser found in MO035, did not seem to decrease the sulphonamide sensitivity either, irrespective of the presence or absence of the Ser-Gly insertion (Table 2). The same result was seen as with the insertion: the $K_{\mathrm{i}}$ for sulphathiazole was higher for the mutant enzyme, but at the same time the $K_{\mathrm{m}}$ for $\mathrm{pAB}$ was raised even more. Therefore, the decrease in affinity for the drug did not result in a higher in vivo resistance level. When considering the $K_{\mathrm{m}}$ for pteridine, the mutations introduced in the BT054 enzyme gave more moderate effects (Table 2). The SerGly insertion approximately doubled the $K_{\mathrm{m}}$ value for pteridine, while the Pro to Ser change at position 68 did not affect the $K_{\mathrm{m}}$ for pteridine at all, nor did it have a significant effect on the generation time of the host cell.

\section{Comparison with plasmid-encoded DHPS mediating sulphonamide resistance}

Remarkably, only two types of plasmid-borne genes encoding sulphonamide-resistant DHPS enzymes (sul1 and sul2) have been found so far, mainly in Gramnegative bacteria (Huovinen et al., 1995). One reason for the ubiquity of these two plasmid-encoded enzymes is that their respective genes are located on very efficient vehicles for dissemination. An additional explanation is that for a DHPS enzyme to be both efficient in its role in folate biosynthesis and to give a high level of resistance to sulphonamides there is a large constraint on the structure of the enzyme to be able to bind both substrates well and to avoid binding the inhibitor. We determined enzyme kinetic parameters for the plasmid-encoded resistant enzymes Sul1 and Sul2, which were found to have lower $K_{\mathrm{m}}$ values for pteridine $(1.8 \mu \mathrm{M}$ and $6.7 \mu \mathrm{M}$, respectively) than the chromosomally encoded resistant DHPS enzymes in meningococci. Sul1 also had a $K_{m}$ for $\mathrm{pAB}$ that was significantly lower, $0.6 \mu \mathrm{M}$, than the values found in resistant meningococcal enzymes. The Sul enzymes have very different amino acid sequences compared to the meningococcal enzymes, so no key amino acids that can explain this difference in $K_{\mathrm{m}}$ values can be identified.

\section{DISCUSSION}

For a competitive inhibition like that involved in sulphonamide action, the possibility that mutational changes affect the affinities of both the inhibitor and substrate has to be considered. In general, one problem with mutations is that changes leading to resistance due to diminished affinity for the inhibitor may also interfere with the affinity for the substrate, and so affect the 
normal function of the enzyme. Therefore, a balance must exist to allow for situations in which discrimination between substrate and inhibitor is necessary, so as not to interfere substantially with the normal activity of the enzyme. The plasmid-encoded DHPS enzymes Sul1 and Sul2 are very well adapted in this regard. They have $K_{\mathrm{m}}$ values for the substrates that are much lower than those seen with chromosomally encoded sulphonamide-resistant enzymes in E. coli and $N$. meningitidis (Swedberg \& Sköld, 1980; this study). At the same time, their $K_{\mathrm{i}}$ values are higher than for any chromosomally encoded enzyme.

Sulphonamide-resistant strains are still present in clinical isolates, although the infections caused by $N$. meningitidis are no longer treated with sulphonamides. We conclude therefore that their DHPS enzymes are well adapted. $K_{\mathrm{m}}$ values for $\mathrm{pAB}$, like those found in resistant meningococcal strains, do not seem to be an evolutionary disadvantage, since sensitive strains with similar properties have been found in clinical isolates (Fermér \& Swedberg, 1997).

When the $K_{\mathrm{m}}$ for pteridine is considered, the picture becomes more complicated. The Sul1 and Sul2 enzymes were found to have $K_{\mathrm{m}}$ values for pteridine similar to those of sensitive meningococcal enzymes. The $K_{\mathrm{m}}$ for pteridine is $1 \cdot 2 \mu \mathrm{M}$ for the E. coli DHPS (Dallas et al., 1992) and $9.3 \mu \mathrm{M}$ for Staphylococcus aureus DHPS (Hampele et al., 1997). $K_{\mathrm{m}}$ values for pteridine as high as the ones found for the chromosomal resistant meningococcal DHPS enzymes thus seem to be unusual, but this does not seem to be an obstacle to growth for these strains. One explanation could be that the $K_{m}$ for pteridine is less important if the dihydropteridine pyrophosphokinase (PPPK) has physical contact with the DHPS enzyme during synthesis. If this is the case, the phosphorylated pteridine could be transferred directly from the PPPK enzyme to the DHPS enzyme and the low affinity for pteridine would then have only a minor effect on the reaction rate. In some eukaryotic organisms, including Plasmodium falciparum and Pneumocystis carinii, the PPPK and DHPS enzymic activities are performed by a single, multifunctional enzyme (Brooks et al., 1994; Triglia \& Cowman, 1994; Volpe et al., 1992). It is therefore possible that these two enzymes also work in co-operation with each other in bacteria.

In $N$. meningitidis, two changes in the amino acid sequence of the DHPS enzyme from strains MO035 and 418 that are important for sulphonamide resistance have been identified. The insertion of two amino acids at position 195-196 is necessary for the resistance, while the residue at position 68 influences the resistance level. The insertion of additional amino acids in the DHPS enzyme, giving rise to sulphonamide resistance, has been reported for Streptococcus pneumoniae (Lopez et al., 1987; Maskell et al., 1997). The importance of the amino acid at position 68 for sulphonamide resistance in laboratory strains of $E$. coli has also been noted (Vedantam et al., 1998), where substitution of Pro by Ser resulted in high-level resistance. Some of the mutations involved in sulphadoxine resistance in Pla. falciparum are found in corresponding parts of the DHPS enzyme (Triglia et al., 1998). Comparisons with the published DHPS structures of E. coli and Sta. aureus revealed that both positions 68 and 195-196 are predicted to be involved in substrate and inhibitor binding (Achari et al., 1997; Hampele et al., 1997), consistent with our findings.

The results presented here can be used to propose a possible route of development of a type 2 resistance gene. The original, sensitive gene had no Ser-Gly insertion, a Pro at position 68 and other unidentified differences compared to the present isolates. The $K_{\mathrm{m}}$ values for both substrates were probably low, as is usual in wild-type, susceptible enzymes. A replication error caused the insertion of two extra amino acids, generating an enzyme with intermediate resistance to sulphonamides, but low affinity for $\mathrm{pAB}$ and pteridine. At this stage, the organism had paid a high cost for the resistance phenotype and had a poorly functioning DHPS enzyme. However, the selection pressure due to the intense use of sulphonamides was sufficiently strong that these bacteria survived. Later, the Pro to Ser substitution at position 68, and possibly other compensatory changes, converted this enzyme into a highly resistant and well adapted enzyme. However, since the original evolution of the resistance gene probably took place in another bacterial species, then it is possible that these two changes alone may have been sufficient to confer high-level resistance. That the resistance evolution probably took place before introduction of the resistance gene into meningococcal strains, is also evident from the identity of a part of the MO035 gene found in strain 418. Both strains have DHPS sequences differing by more than $10 \%$ from those of susceptible strains, but the lengths of the replaced segments are considerably different. This finding indicates two different transfer events leading to the generation of the two strains. The change at position 68 in strain 418 must have occurred after the introduction of the foreign DNA, since this amino acid is located outside the replaced region (Fig. 1). This further illustrates the importance of residue 68 for a well adapted resistant type 2 enzyme. If any other mutation in the enzyme is of importance it is hard to identify because of the many remaining differences to the wild-type sequence in the part of the enzyme that is common to 418 and MO035.

When the two changes, identified as important for sulphonamide resistance in type 2 enzymes, were introduced into the sensitive enzyme from BT054, no meaningful increase in the resistance phenotype was seen (Table 2). The modified enzyme is also less able to perform its natural enzymic function, shown by raised $K_{\mathrm{m}}$ values for its substrates as well as supporting a slower growth rate when cloned in a folP-deficient $E$. coli strain. These findings indicate not only that additional changes to DHPS are necessary to develop resistance, but also that it may be difficult to create a resistance gene from a sensitive meningococcal gene by simply introducing sequentially the mutations found in 
the type 2 resistance genes. The wild-type meningococcal enzymes may differ too much from the type 2 resistant enzymes for such in vitro evolution. The results presented here thus give further evidence for the horizontal-transfer theory of sulphonamide-resistance acquirement, where the type 2 genes are thought to originate from a different organism. Earlier attempts to find the origin of the resistance gene suggested that it may not be derived from commensal Neisseria species, since their available folP sequences are more similar to those from susceptible than from resistant $N$. menigitidis (Fermér et al., 1995; Fermér \& Swedberg, 1997). This is in contrast to what has been found earlier for penicillinbinding proteins conferring penicillin resistance in $N$. meningitidis and Str. pneumoniae, where in both cases related commensal species could be identified as the source of the resistance genes (Spratt, 1994).

\section{ACKNOWLEDGEMENTS}

This work was supported by a grant from the Swedish Medical Research Council. We also thank the student Tina Olsson for help with mutagenesis and enzymic assays.

\section{REFERENCES}

Achari, A., Somers, D. O., Champness, J. N., Bryant, P. K., Rosemond, J. \& Stammers, D. K. (1997). Crystal structure of the anti-bacterial sulphonamide drug target dihydropteroate synthase. Nat Struct Biol 4, 490-497.

Bertani, G. (1951). Studies on lysogenesis. I. The mode of phage liberation by lysogenic Escherichia coli. J Bacteriol 62, 293-300.

Björkman, J., Hughes, D. \& Andersson, D. I. (1998). Virulence of antibiotic-resistant Salmonella typhimurium. Proc Natl Acad Sci USA 95, 3949-3953.

Brooks, D. R., Wang, P., Read, M., Watkins, W. M., Sims, P. F. G. \& Hyde, J. E. (1994). Sequence variation of the hydroxymethyldihydropterin pyrophosphokinase: dihydropteroate synthase gene in lines of the human malaria parasite, Plasmodium falciparum, with differing resistance to sulphadoxine. Eur J Biochem 224, 397-405.

Dallas, W. R., Gowen, J. E., Ray, P. H., Cox, M. J. \& Dev, K. I. (1992). Cloning, sequencing and enhanced expression of the dihydropteroate synthase gene of Escherichia coli MC4100. J Bacteriol 174, 5961-5970.

Dower, W. J., Miller, J. F. \& Ragsdale, C. W. (1988). High efficiency transformation of E. coli by high voltage electroporation. Nucleic Acids Res 16, 6127-6145.

Fermér, C. \& Swedberg, G. (1997). Adaptation to sulphonamide resistance in Neisseria meningitidis may have required compensatory changes to retain enzyme function: kinetic analysis of dihydropteroate synthases from $N$. meningitidis expressed in a knockout mutant of E. coli. J Bacteriol 179, 831-837.

Fermér, C., Kristiansen, B.-E., Sköld, O. \& Swedberg, G. (1995). Sulphonamide resistance in Neisseria meningitidis as defined by site-directed mutagenesis could have its origin in other species. $J$ Bacteriol 177, 4669-4675.

Hampele, I. C., D'Arcy, A., Dale, G. E. \& 7 other authors (1997). Structure and function of the dihydropteroate synthase from Staphylococcus aureus. J Mol Biol 286, 21-30.
Huovinen, P., Sundström, L., Swedberg, G. \& Sköld, O. (1995). Trimethoprim and sulphonamide resistance. Antimicrob Agents Chemother 39, 279-289.

Levin, B. R., Lipsitch, M., Perrot, V., Schrag, S., Antia, R., Simonsen, L., Moore Walker, N. \& Stewart, F. M. (1997). The population genetics of antibiotic resistance. Clin Infect Dis 24, S9-S16.

Lopez, P., Espinosa, M., Greenberg, B. \& Lacks, S. A. (1987). Sulphonamide resistance in Streptococcus pneumoniae: DNA sequence of the gene encoding dihydropteroate synthase and characterization of the enzyme. J Bacteriol 169, 4320-4326.

Maskell, J. P., Sefton, A. M. \& Hall, L. M. C. (1997). Mechanism of sulphonamide resistance in clinical isolates of Streptococcus pneumoniae. Antimicrob Agents Chemother 41, 2121-2126.

Müller-Hill, B., Crapo, L. \& Gilbert, W. (1968). Mutants that make more lac repressor. Proc Natl Acad Sci USA 59, 1259-1264.

Rådström, P., Fermér, C., Kristiansen, B.-E., Jenkins, A., Sköld, O. \& Swedberg, G. (1992). Transformational exchanges in the dihydropteroate synthase gene of Neisseria meningitidis: a novel mechanism for acquisition of sulphonamide resistance. J Bacteriol 174, 6386-6393.

Sarkar, G. \& Sommer, S. S. (1990). The 'megaprimer' method of site-directed mutagenesis Biotechniques 8, 404-407.

Schrag, S. J. \& Perrot, V. (1996). Reducing antibiotic resistance. Nature 381, 120-121.

Spratt, B. G. (1994). Resistance to antibiotics mediated by target alterations. Science 264, 388-393.

Stuart, F. M., Antia, R., Levin, B. R., Lipsitch, M. \& Mittler, J. E. (1998). The population genetics of antibiotic resistance II : analytic theory for sustained populations of bacteria in a community of hosts. Theor Popul Biol 53, 152-165.

Swedberg, G. \& Sköld, O. (1980). Characterization of different plasmid-borne dihydropteroate synthases mediating bacterial resistance to sulphonamides. J Bacteriol 142, 1-7.

Triglia, T. \& Cowman, A. F. (1994). Primary structure and expression of the dihydropteroate synthase gene of Plasmodium falciparum. Proc Natl Acad Sci USA 91, 7141-7153.

Triglia, T., Wang, P., Sims, P. F. G., Hyde, J. E. \& Cowman, A. F. (1998). Allelic exchange at the endogenous genomic locus in Plasmodium falciparum proves the role of dihydropteroate synthase in sulphadoxine-resistant malaria. EMBO $J$ 17, 3807-3815.

Vandeyar, M. A., Weiner, M. P., Hutton, C. J. \& Batt, C. A. (1988). A simple and rapid method for the selection of oligodeoxynucleotide-directed mutants. Gene 65, 129-133.

Vedantam, G., Guay, G. G., Austria, N. E., Doktor, S. Z. \& Nichols, B. P. (1998). Characterization of mutations contributing to sulphathiazole resistance in Escherichia coli. Antimicrob Agents Chemother 42, 88-93.

Volpe, F., Dyer, M., Scaife, J. G., Darby, G., Stammers, D. K. \& Delves, C. J. (1992). The multifunctional folic acid synthesis fas gene of Pneumocystis carinii appears to encode dihydropteroate synthase and hydroxymethyldihydropterin pyrophosphokinase. Gene 112, 213-218.

Yannisch-Perron, C., Vieira, J. \& Messing, J. (1985). Improved M13 phage cloning vectors and host strains: nucleotide sequences of the M13mp18 and pUC19 vectors. Gene 33, 103-119.

Received 23 August 1999; revised 6 December 1999; accepted 17 January 2000. 